https://doi.org/10.15407/ujpe64.12.1154

\title{
TO THE MEMORY OF MOISEI ISAAKOVYCH KAGANOV
}

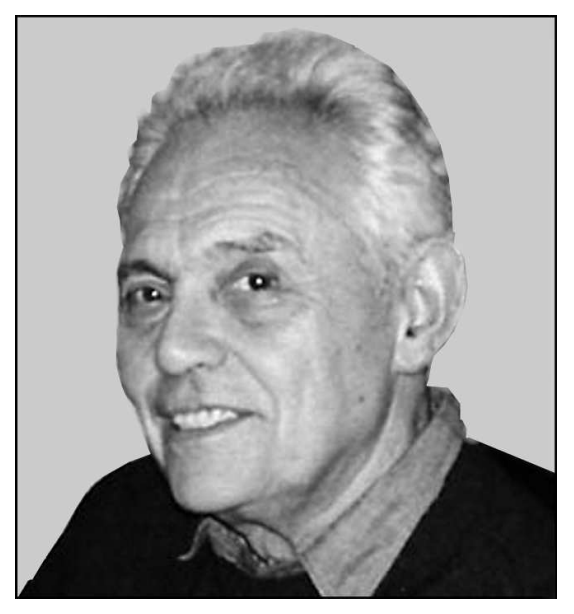

On August 31, 2019, Professor Moisei Isaakovych Kaganov - an outstanding physicist-theorist, a talented popularizer of science, and an extraordinary personality - passed away in the 99th year of his life.

Moisei Isaakovych was born on June 4, 1921. His mother Dina Davydivna was a specialist pediatrician. His father Isaak Yakovych Kaganov was a wellknown philologist, a disciple of Academician O. Biletskyi, and worked at the Kharkiv University. The childhood of M.I. passed in Kharkiv, but he finished school in Kyiv, where his parents moved after the capital of the Ukrainian SSR had been relocated from Kharkiv to Kyiv in 1934. The terror of the 1930s bypassed Kaganov's family.

When being a schoolboy, Musik - in such a way the young M.I. introduced himself to everyone - was so impressed by popular books on physics that he felt a call to devote himself to this science. "The best physics in Ukraine was in Kharkiv", M.I. recalled, and after finishing school in 1939, he entered the Faculty of Physics and Mathematics at the Kharkiv University. But his education lasted for a few months only,

1154 because he was called to the army. He met World War II as a sailor of a coastal artillery battery located near the town of Tuapse. At the war, M.I. was awarded the "soldier" Order of the Red Star. After the war, M.I. was demobilized and returned to the University at the end of 1945. In order to make up seven army years, he skipped over one educational year and graduated from the Faculty of Physics and Mathematics in 1949.

At that time, the Faculty of Physics at the Kharkiv University was a basic staff-training institution for the Soviet atomic project headed by I.V. Kurchatov. This training was carried out in cooperation with a secret section of the Ukrainian Physico-Technical Institute (UPTI). The section was created for the fulfillment of large-scale tasks and was called "Laboratory No. 1". O.I. Akhiezer and I.M. Lifshits the heads of theoretical departments at "Laboratory No. 1" - also lectured at the University. After the graduation from the University, M.I. was enrolled in the department headed by Illya Mykhailovych Lifshits, who became his teacher and, later, a senior friend.

Moisei Isaakovych worked at the UPTI from 1949 to 1970 . The main direction of his research activity included the quantum theory of solid state, in particular, the theory of metals and the theory of magnetism at low temperatures. Together with I.M. Lifshits and his disciples (M.A. Azbel, E.A. Kaner, and V.G. Pishchanskyi), he carried out a series of classic works on the electron theory of metals. Those works formed a basis for a new direction in solid state theory, which was called "fermiology". The results of corresponding researches were summarized in the monograph by Lifshits, Azbel, and Kaganov "Electron Theory of Metals" [1], which was published in 1971, as well as in a number of reviews [2-5]. The book "Elec-

ISSN 2071-0194. Ukr. J. Phys. 2019. Vol. 64, No. 12 
tron Theory of Metals" has been a handbook of solidstate physicists for many years.

In the framework of the issues that Laboratory No. 1 dealt with, Moisei Isaakovych participated in the studies of the dynamics and kinetics of radiation damages induced in metals by high-energy ions. For a long time, the results obtained have been stored only in reports classified as top-secret, but ultimately they were published $[6,7]$. The calculation of the ion decelerating force was based on a scenario of the sequential energy transfer: first, to electrons and, afterward, to phonons and crystal lattice deformations. In work [6], a mechanism according to which the interaction between electrons and phonons leads to radiation-induced changes in the tracks of heavy ions was considered for the first time in the world. The results obtained in this work are still used in researches on the degradation of materials used in nuclear reactors. In work [7], a method for the calculation of radiation damages was proposed. It has 450 citations. This is a rather large number even now, to say nothing of the mid-twentieth century with its different culture of references to the works of other authors.

Issues dealing with magnetism were developed by M.I. in collaboration with O.I. Akhiezer, V.M. Tsukernik, V.G. Bar'yakhtar, and S.V. Peletminskii. It should be noted that, in the late 1940s, the understanding of excitations in magnets was reduced to the articles written by Felix Bloch and to the Holstein-Primakoff method. Nobody was sure how to deal with antiferromagnets. Coryphaei of science e.g., L.D. Landau - thought that, first of all, the issues associated with the ground state of antiferromagnets had to be elucidated. Therefore, the theory of spin waves developed with the participation of M.I. became a principal step ahead. Its results were summarized in review [8,9] written by M.I. together with O.I. Akhiezer and V.G. Bar'yakhtar and published in 1960. Later, this review served as a basis for the famous book "Spin Waves" [10] written by O.I. Akhiezer, V.G. Bar'yakhtar, and S.V. Peletminskii and published in 1967. M.I. did not coauthor this book because he concentrated his efforts on the "Electron Theory of Metals". M.I. noted himself that his scientific and popular publications were devoted to the physics of three basic solid-state quasiparticles: electrons, phonons, and magnons.

ISSN 2071-0194. Ukr. J. Phys. 2019. Vol. 64, No. 12
In 1952-1970, M.I. combined his work at the UPTI with the lecturing at the Chair of Statistical Physics and Thermodynamics (since 1979, this is the Chair of Theoretical Physics) of the Kharkiv University. For many years, he taught the undergraduate courses "Quantum Theory of Metals" and "Atomic and Nuclear Physics".

The activity of theoretical groups at the UPTI was substantially connected with L.D. Landau and his Moscow collaborators. Therefore, M.I. repeatedly made reports on his work at Landau's seminar. The communication between M.I. and L.D. Landau was two-way. In the 1970s, P.L. Kapitsa invited I.M. Lifshits to head (after L.D. Landau) the theoretical department at the Institute of Physical Problems (IPP). M.I. also moved to Moscow together with his teacher. He held the positions of Senior Research Fellow at the Theoretical Department of the IPP and Professor at the Moscow State University (MSU). As a professor, he brought many talented graduate students from the MSU to the IPP. For instance, Andrey V. Chubukov, one of the most successful graduate students of M.I., is now working at the William I. Fine Theoretical Physics Institute in the University of Minnesota (USA).

Moisei Isaakovych had taught several generations of students. In 1998, the Wrocław University of Technology (Poland) awarded him the title of Honorary Doctor for his merits in scientific and educational activities. I.M. had been fruitfully working at the IPP till 1994. A complete list of his scientific publications (without popular ones) contains more than 230 items. Simultaneously, he maintained close relations with Kharkiv physicists: he frequently visited the Physico-Technical Institute of Low Temperatures (he was pleased to remember this institute and kept a permanent pass to it), the University, and physical groups at other institutions. He regularly came to conferences on low-temperature physics of metals, which were held by the Donetsk Institute of Physics and Technology in the village of Staryi Karavan. He remained to be a member of the editorial board of the journal Fizika Nizkikh Temperatur (Low Temperature Physics).

A bright section in the creative heritage of M.I. is composed by his popular scientific publications. In his memoirs, he recalled that, when he studied at secondary school, a famous popular book by M.P. Bronshtein "Solar Substance" [11] - yet not forbidden at 
that time - got into his hands. This book substantially affected the choice by M.I. of his creative pathway. So, M.I. knew from his own experience about the importance of the high-quality popular scientific literature. Besides books, Moisei Isaakovych is the author of numerous brochures published by the Znannya (Knowledge) Society and papers published in the Priroda (Nature) journal. The most famous among popular books written by M.I. is "Electrons, Phonons, Magnons" [12]. The next in popularity is the book "The Nature of Magnetism" [13], which he co-authored with V.M. Tsukernik. The both indicated books can be seen on the tables of many practical physicists. Already after moving to the United States, M.I. together with G.Ya. Lubarskii published a remarkable book "Abstraction in Mathematics and Physics" [14].

In 1994, Moisei Isaakovych retired and moved to the United States to the city of Boston, where his children lived. However, only conditionally could he be regarded as a pensioner. He liked to say, "I am working, but not at the work". He continued to be interested in science and the affairs of his colleagues. Articles, reviews, and books written by Moisei Isaakovych and devoted to various domains of theoretical physics, as well as memoirs about physicists, were regularly published.

He was gone, but the blessed memory of Moisei Isaakovych Kaganov will forever be preserved in the hearts of his many colleagues, disciples, and everybody who knew this kind, always friendly and optimistic person.

1. I.M. Lifshits, M.Ya. Azbel, M.I. Kaganov. Electron Theory of Metals (Nauka, 1971) (in Russian) [I.M. Lifshitz, M.Ya. Azbel, M.I. Kaganov. Electron Theory of Metals (Springer, 1973)].

2. I.M. Lifshits, M.I. Kaganov. Some problems of the electron theory of metals. I. Classical and quantum mechanics of electrons in metals. Usp. Fiz. Nauk 69, 419 (1959) (in Russian).
3. I.M. Lifshits, M.I. Kaganov. Some problems of the electron theory of metals. II. Statistical mechanics and thermodynamics of electrons in metals. Usp. Fiz. Nauk 78, 411 (1962) (in Russian).

4. I.M. Lifshits, M.I. Kaganov. Some problems of the electron theory of metals. III. Kinetic properties of electrons in metals. Usp. Fiz. Nauk 87, 389 (1965) (in Russian).

5. M.I. Kaganov, I.M. Lifshits. Electron theory of metals and geometry. Usp. Fiz. Nauk 129, 487 (1979) (in Russian).

6. I.M. Lifshits, M.I. Kaganov, L.V. Tanatarov. To the theory of radiation changes in metals. At. Energ. 6, 391 (1959) (in Russian) [I.M. Lifshits, M.I. Kaganov, L.V. Tanatarov. To the theory of radiation changes in metals. J. Nucl. Energ. A 12, 69 (1960)].

7. M.I. Kaganov, I.M. Lifshits, L.V. Tanatarov. Relaxation between electrons and lattice. Zh. Ėksp. Teor. Fiz. 31, 232 (1956) (in Russian).

8. A.I. Akhiezer, V.G. Bar'yakhtar, M.I. Kaganov. Spin waves in ferromagnets and antiferromagnets. I. Usp. Fiz. Nauk 71, 533 (1960) (in Russian).

9. A.I. Akhiezer, V.G. Bar'yakhtar, M.I. Kaganov. Spin waves in ferromagnets and antiferromagnets. II. Usp. Fiz. Nauk 72, 3 (1960) (in Russian).

10. A.I. Akhiezer, V.G. Bar'yakhtar, S.V. Peletminskii. Spin Waves (Nauka, 1967) (in Russian) [A.I. Akhiezer, V.G. Bar'yakhtar, S.V. Peletminskii. Spin Waves (North Holland, 1968)].

11. M.P. Bronstein. Solar Substance (Detizdat, 1936) (in Russian) [M.P. Bronstein. Solar Substance. Kvant Library Series, No. 80 (Nauka, 1990) (in Russian)].

12. M.I. Kaganov. Electrons, Phonons, Magnons (Nauka, 1979) (in Russian).

13. M.I. Kaganov, V.M. Tsukernik. The Nature of Magnetism. Kvant Library Series, No. 16 (Nauka, 1982) (in Russian).

14. M.I. Kaganov, G.Ya. Lubarskii. Abstraction in Mathematics and Physics (Fizmatlit, 2005) (in Russian).

YA.B. BAZALIY (USA),

O.S. BAKAI (Ukraine), V.G. BAR'YAKHTAR (Ukraine), V.M. LOKTEV (Ukraine), $L U Y U$ (China) 